\title{
El espectáculo en las sociedades modernas: a propósito de dos tesis de Debord ${ }^{1}$ The spectacle in modern societies: on two theses by Debord
}

Recibido: 16 de octubre de 2015 - Revisado: 16 de mayo de 2016 - Aceptado: 24 de agosto de 2016.

Jorge Manuel Escobar Ortiz ${ }^{2}$

\section{Resumen}

En este artículo, hago una evaluación crítica de dos tesis de Guy Debord sobre el lugar del espectáculo en las sociedades modernas, según el primer capítulo de La société du spectacle. La primera plantea que el espectáculo no persigue ningún fin más allá de sí mismo. La segunda, que la prevalencia del espectáculo en las sociedades modernas justifica la creencia en una dicotomía entre apariencia y realidad. A partir del análisis de la comunicación científica y la propaganda, elevo algunas dudas sobre la primera. A partir de la crítica filosófica a la dicotomía, muestro lo mismo para la segunda. Mi conclusión indaga sobre la pertinencia de estas dos tesis al analizar el lugar del espectáculo en las sociedades modernas.

\section{Palabras clave}

Espectáculo, sociedades modernas, comunicación científica, propaganda, dicotomía entre apariencia y realidad.

\begin{abstract}
In this article, I make a critical assessment of two theses by Guy Debord on the place of the spectacle in modern societies, according to the first chapter of La société du spectacle. The first poses that the spectacle pursues no end beyond itself. The second is that the prevalence of the spectacle in modern societies justifies the belief in a dichotomy between appearance and reality. From the analysis of scientific communication and propaganda, I raise some doubts about the first. From philosophical criticism to the dichotomy, I show the same for the second. My conclusion inquiries about the relevance of these two theses in analyzing the place of the spectacle in modern societies.
\end{abstract}

\section{Keywords}

Spectacle, modern societies, scientific communication, propaganda, dichotomy between appearance and reality.
${ }^{1}$ Artículo realizado en el marco del proyecto "Caracterización, modelamiento y simulación de las reglas de racionalidad tecnológica en el uso y consumo de tecnología", suscrito entre el Instituto Tecnológico Metropolitano, la Universidad de Antioquia, la Universidad Nacional de Colombia, sede Bogotá y Medellín, e Intersoftware.

2 Filosófo de la Universidad de Antioquia, M.A. en Filosofia de la Universidad de Manitoba, Canadá y M.A. en Historia y Filosofia de la Ciencia de la Universidad de Notre Dame, Estados Unidos. Candidato a Ph.D. en Ciencias Sociales y Humanas de la Universidad Nacional de Colombia. Actualmente miembro del grupo Ciencia, Tecnología y Sociedad más innovación (CTS+i) del Instituto Tecnológico Metropolitano de Medellín y docente de la maestría en Estudios de Ciencia, Tecnología, Sociedad, e Innovación de la misma institución. Correo electrónico: jorgeescobar@itm.edu.co

Para citar este artículo use: Escobar, J. (2017). El espectáculo en las sociedades modernas: a propósito de dos tesis de Debord. Civilizar Ciencias Sociales y Humanas, 17(32), 245 256. Doi: $10.22518 / 16578953.829$ 


\section{Introducción}

La société du spectacle de Guy Debord apareció en 1967, y desde entonces ha recibido gran atención, con múltiples ediciones en francés, traducciones a diferentes idiomas, un buen número de citaciones y literalmente miles de visitas en las distintas páginas de Internet que recogen su versión audiovisual, realizada por el propio Debord en 1973. Con base en factores como estos, Kaplan (2012) afirma que el libro ha obtenido el estatus de un clásico de culto en la crítica cultural contemporánea, y por ese motivo, él destaca la importancia de emprender un análisis de los conceptos que allí se presentan.

Mi interés en este artículo es precisamente emprender uno de esos análisis. En particular, me propongo concentrarme en dos tesis que Debord (1992) presenta sobre el concepto del espectáculo en el primer capítulo de su libro, a saber: que el espectáculo no persigue ningún fin más allá de sí mismo y que la prevalencia del espectáculo en las sociedades modernas justifica la creencia en una dicotomía entre apariencia y realidad. Mi propósito es mostrar que ambas tesis son problemáticas desde un punto de vista epistémico, político e incluso existencial. Pero para alcanzar estos objetivos, quiero empezar por aclarar un par de puntos.

En primer lugar, mi pretensión no es en ningún momento hacer una crítica de la obra de Debord tomada en su totalidad. Esto es importante porque tal crítica sería no solo mucho más ambiciosa, sino que tendría alcances mucho más amplios y profundos que aquellos que me he trazado para este artículo. Una crítica así puede encontrarse en Kaplan (2012), que abiertamente busca develar las contradicciones internas que él observa en el libro de Debord, particularmente con respecto a lo que él ve como una mezcla ambigua entre liberalismo y marxismo en el tratamiento de conceptos como masas alienadas y colectivo revolucionario. Sin embargo, como ya he indicado, este no es mi propósito. Por tanto, queda en manos de otros determinar si mi evaluación de las dos tesis de Debord en que me enfoco aquí contribuye o no a reforzar ese tipo de críticas globales sobre su obra.

El segundo punto se relaciona con el anterior, y es que tampoco pretendo explorar las raíces intelectuales de las ideas de Debord. Esto no significa que niegue la importancia de emprender este tipo de estudios, que tienen un corte histórico. Por ejemplo, el libro de Jappe (1999) es una fuente ya clásica en este sentido. Él se ocupa de explorar con detalle los vínculos de Debord con filósofos como Hegel, Marx y Lukács y el movimiento inspirado por la Internacional Situacionista, con el fin de ofrecer una mirada mucho más abarcadora de su obra. Y aunque sin duda esto abre un panorama muy interesante sobre muchos de sus planteamientos, el foco principal en ese caso es establecer qué tan cercano o lejano se mantuvo Debord a sus orígenes intelectuales. Mi foco, en cambio, es establecer qué tan adecuadas son las dos tesis de que me ocupo en este artículo para hacer un análisis del lugar del espectáculo en las sociedades modernas. En otras palabras, mi interés es evaluar esas dos tesis, y no propiamente hacer una reconstrucción histórica de ellas. Si el artículo se lee desde esa perspectiva histórica, el lector sin duda quedará con muchos interrogantes cuya respuesta no encontrará aquí, pero que tampoco pretendo responder en ningún momento. Mi objetivo es exclusivamente elaborar una evaluación crítica de esas dos tesis de Debord en la comprensión de las sociedades modernas. Y para eso presento evidencia tomada de la comunicación pública de la ciencia y la tecnología, la propaganda y el análisis filosófico de la dicotomía entre apariencia y realidad.

En la siguiente sección empiezo por reconstruir las dos tesis de Debord. Luego dedico dos secciones a la evaluación crítica de cada una de ellas. Por último, termino con una sección de conclusiones que redondea y sistematiza lo planteado en el resto del artículo. 


\section{Dos tesis sobre el espectáculo}

Debord (1992) presenta sus dos tesis sobre el espectáculo en las sociedades modernas en el primer capítulo de su libro La société du spectacle $^{1}$. En esta sección, me concentro en la reconstrucción de cada una de ellas, con el fin de emprender posteriormente su evaluación crítica.

En primer lugar, Debord indaga acerca de la finalidad del espectáculo y concluye que este no persigue ningún fin más allá de sí mismo. En el caso del espectáculo, sus medios son al mismo tiempo sus fines ["ses moyens sont en même temps son but"] (Cap. 1, §13). O de un modo más contundente, Debord sostiene que, en el caso del espectáculo, el fin no existe, sino que más bien su desarrollo lo es todo, pues la razón de ser del espectáculo no es más que alcanzarse a sí mismo ["dans le spectacle, image de l'économie régnante, le but n'est rien, le développement est tout. Le spectacle ne veut en venir à rien d'autre qu'à lui-même] (Cap. 1, §14).

Debord parece sugerir en estos pasajes que el uso del espectáculo en las sociedades modernas no tiene como fin nada diferente al espectáculo en sí mismo. El espectáculo no se emplea como un medio para alcanzar otros fines, sean más elevados o más bajos, de acuerdo con la valoración que alguien quisiera hacer de ellos, sino como un medio cuyo fin es el mismo medio. En estas sociedades, se recurre al espectáculo para permanecer en el espectáculo, no para transitar hacia algo distinto a él mismo.

En segundo lugar, Debord retoma la tradicional dicotomía filosófica entre apariencia y realidad, pero mediada ahora por el concepto de espectáculo. El espectáculo es para Debord, como acaba de verse, un fin en sí mismo. Pero además los ciudadanos de las sociedades modernas son incapaces de vivir por fuera de él. De estas dos premisas, Debord infiere que los ciudadanos de las sociedades modernas han perdido la capacidad de acceder directamente a la realidad y han terminado por contentarse con un mundo de apariencias.

En estas sociedades, la vida aparece como una inmensa acumulación de espectáculos, y por ello todo lo que antes se vivía directamente ahora se vive como una representación ["toute la vie des sociétés dans lesquelles règnent les conditions modernes de production s'annonce comme une immense accumulation de spectacles. Tout ce qui était directement vécu s'est éloigné dans une représentation"] (Cap. 1, §1, sus cursivas). De acuerdo con Debord, el espectáculo priva a los ciudadanos de estas sociedades de un vínculo directo con el mundo real, y más bien les ofrece mediaciones que impiden siempre la aprehensión directa de ese mismo mundo real. Esto va en contravía de lo que sucedía en otras épocas, cuando prevalecía el sentido del tacto sobre el sentido espectacular de la vista ["le spectacle, comme tendance à faire voir par différentes médiations spécialisées le monde qui n'est plus directement saisissable, trouve normalement dans la vue le sens humain privilégié qui fut à d'autres époques le toucher"] (Cap. 1, §18).

Toda esta situación deriva en un estado de alienación en los ciudadanos, que no logran ya vivir sus propias vidas y mucho menos comprenderlas. Viven sus vidas en el espectáculo, como productos de este, pero alejados irremediablemente de su vida real, que yace agazapada bajo ese mundo de apariencias.

Debord sostiene, en suma, dos tesis que resultan complementarias entre sí: (i) el espectáculo no persigue ningún fin más allá de sí mismo y (ii) la prevalencia del espectáculo en las sociedades modernas justifica la creencia en una dicotomía entre apariencia y realidad. $\mathrm{Mi}$ propósito en este artículo es minar ambas tesis, y por ese medio, elevar dudas sobre su utilidad para comprender el lugar del espectáculo en las sociedades modernas.

Para esto, empiezo por analizar la tesis de los fines del espectáculo a partir de dos fe- 
nómenos de las sociedades modernas en que se recurre permanentemente a él, a saber: la comunicación científica y la propaganda. Mi objetivo es mostrar que en ambos casos el espectáculo se emplea con una intención que va más allá del espectáculo mismo, una intención que incluso puede juzgarse como positiva o negativa, de acuerdo con los sujetos bajo consideración. Luego paso a analizar la tesis de la dicotomía, con el objeto de destacar el tipo de compromisos ontológicos y epistemológicos que envuelve, y las consecuencias existenciales que trae para el estudio del lugar del espectáculo en las sociedades modernas.

\section{Los fines del espectáculo}

En esta sección arguyo que el uso que se hace del espectáculo en las sociedades modernas tiene fines que no se reducen de ningún modo al espectáculo mismo. Por el contrario, el espectáculo se emplea en ellas como una excusa para alcanzar otros fines, fines con amplios alcances epistémicos y políticos. Para ello me sirvo del análisis de dos fenómenos que resultan centrales, y en ocasiones interconectados, en estas sociedades. Estos fenómenos son la comunicación científica y la propaganda.

\section{El caso de la comunicación cientí- fica.}

Piénsese, para empezar, en lo que sucede con los procesos de comunicación del conocimiento científico al gran público. Sea que esto se realice en espacios como museos y centros interactivos o por medios escritos (e.g., artículos de revistas o periódicos), orales (e.g., presentaciones y conferencias), sonoros (e.g., programas radiales y podcasts) o audiovisuales (e.g., documentales), todos los procesos de comunicación del conocimiento científico recurren de alguna $u$ otra forma al uso de procedimientos que caen bajo la categoría de espectáculo dada por Debord. El punto es que los fines de estos procesos de comunicación no son los procesos mismos de comunicación. El espectáculo se emplea en ellos como un medio para alcanzar otros fines. La pregunta es: ¿qué fines?

Una primera forma de responder a esta pregunta es apelar a aquellas tendencias contemporáneas que ubican el problema de la comunicación científica en el marco de los Estados democráticos. Autores como Alcíbar(2015), Arias (2011), Durant (1999), Erazo (2007), Hermelin (2011), Jiménez y Palacio (2010), Lozano (2008), Olivé (2003), Perrault (2013), Pinzón, Franco-Avellaneda y Falla (2015), Rueda (2016) y Ursua (2004), por mencionar solo algunos nombres, hacen énfasis en la importancia de diseñar modelos democráticos de comunicación científica que tengan como propósito garantizar la participación ciudadana en ciencia y tecnología. Desde esta perspectiva, la finalidad de la comunicación científica es precisamente servirse del espectáculo como un medio que abre posibilidades no solo de democratización de la ciencia y la tecnología, sino que además contribuye al fortalecimiento de la democracia en los países. Pues la comunicación científica se entiende en este contexto como un principio democrático fundamental para la ilustración del gran público y el mejoramiento del bienestar y la calidad de vida de toda la sociedad.

Para estas tendencias teóricas, con la comunicación científica se busca la democratización tanto del acceso al conocimiento científico como de la toma de decisiones sobre qué hacer con él por parte de la sociedad. Y esto en términos de Cuevas (2008), que analiza las relaciones entre conocimiento científico, participación ciudadana y democracia, permite afirmar que una finalidad de la comunicación científica es formar ciudadanos con conocimientos científicos cada vez más sólidos. El supuesto aquí es que entre mejor sea su conocimiento, mejor y mayor será también su participación en cuestiones de ciencia y tecnología que los afectan directa e indirectamente. Y lo contrario también es cierto: entre mejor y mayor sea su participación, mejor será la calidad de sus conocimien- 
tos científicos. El espectáculo funciona en estos modelos de comunicación científica como un medio hacia un fin mucho más elevado, que no es otro que la formación de ciudadanos mejor informados, más críticos y más proactivos en temas de ciencia y tecnología en la sociedad.

Pero a la comunicación científica puede atribuírsele un fin distinto también. Rider (1990), por ejemplo, abiertamente trata el experimento científico como una forma de espectáculo. Él traza su historia hasta los comienzos de la época moderna, y lo vincula con los procedimientos de la magia natural, en términos de los diferentes fines educativos e intelectuales que se perseguían con él en escenarios públicos, universidades y salones privados, sin renunciar por ello a su carácter espectacular. Esto concuerda con otras perspectivas similares, como la aproximación de Golinski (1992) a la historia de la química a finales del siglo XVIII y comienzos del XIX.

Golinski (1992) plantea que la ciencia es un tipo de conocimiento público que se entiende mucho mejor si uno se concentra en formas y lugares de producción de conocimiento enmarcados por una vida cultural particular, y no en la búsqueda de conocimiento objetivo o en una diseminación adecuada de la verdad. Él no se interesa, por tanto, en lo que sería el desarrollo teórico de la química en el período de su estudio (1760-1820), es decir, en cómo algunos debates teóricos llevaron a la formulación de las teorías químicas que aceptamos hoy en día. Su meta es más bien comprender de qué manera las comunidades científicas construyen y transforman sus audiencias de acuerdo con diversas condiciones históricas. Y para alcanzar este objetivo, propone dos tesis.

La primera es la tesis del componente privado de la ciencia. De acuerdo con esta tesis, los científicos producen hechos empíricos en locaciones muy específicas y concretas (es decir, los laboratorios), y de acuerdo con recursos y habilidades muy particulares. Por tanto, la ciencia necesariamente involucra un componente privado, pues no todo el mundo tiene acceso a esas locaciones, esos recursos y esas habilidades.

La segunda es la tesis del componente público de la ciencia. De acuerdo con esta tesis, la ciencia se hace pública gracias a dos factores, que resultan complementarios entre sí. De una parte, sus formas de discurso, que pueden verse como diversos tipos de retórica. Por otra parte, su habilidad para traducir los hechos, los instrumentos y las técnicas del laboratorio a nuevos contextos por fuera del laboratorio.

Golinski aplica la perspectiva abierta por la conjunción de estas dos tesis a la historia de la química, y encuentra que se ajusta muy bien. Él muestra que Cullen y Black, Priestley, Lavoisier y Davy ciertamente llevaron a cabo su trabajo en locaciones particulares (sus laboratorios) y aplicaron habilidades y recursos específicos en cada caso. Pero asimismo cada uno de ellos apeló a diferentes formas de discurso, con sus características retóricas propias, para traducir los hechos, los instrumentos y las técnicas del laboratorio a audiencias situadas por fuera del laboratorio y que terminaron por darles su respaldo.

Cullen y Black, por ejemplo, comunicaron sus resultados casi exclusivamente en un contexto universitario y por medios retóricos que hacían énfasis en la capacidad de la ciencia para mejorar la sociedad. Pero esta focalización en los contextos universitarios les impidió hacer de la química una disciplina realmente pública, pues la confinó al contexto universitario. Priestley y Davy, por el contrario, habrían alcanzado esta meta, a pesar de sus diferencias acerca del rol del público en la producción del conocimiento científico. Priestley pensaba que el público debía tener un rol activo en la producción de ese conocimiento, que en cierto modo el laboratorio debía ir al público, y por eso publicaba libros y hacía demostraciones que invitaban al público a participar en la producción de conocimiento químico. Davy, en cambio, le dio un rol más 
bien pasivo a ese público, como espectador $\mathrm{y}$ financiador de sus procesos de producción de conocimiento químico. El público estaba invitado al laboratorio, e incluso pagaba por asistir, pero solo para presenciar el espectáculo de las demostraciones del propio Davy, y de ese modo ilustrarse acerca del nuevo conocimiento químico que se estaba produciendo en la época. Finalmente, Lavoisier conscientemente intentó restringir el rol de su público mediante la reformulación del lenguaje químico y el diseño de instrumentos y experimentos cuya complejidad los hacía de difícil reproducción por fuera de las condiciones de su laboratorio.

Los trabajos de Rider y Golinski sugieren, en definitiva, que aun cuando claramente involucre aspectos que pueden identificarse con el espectáculo, la comunicación científica de ningún modo se reduce al espectáculo mismo. Su finalidad se aprecia mucho mejor si se piensa en ella como el esfuerzo de una comunidad científica por persuadir a un público concreto acerca de sus teorías, y ganar así su apoyo intelectual, social y financiero para continuar desarrollando sus programas de investigación.

La presencia del espectáculo en los procesos de comunicación científica puede entenderse, entonces, desde al menos dos perspectivas diferentes. De un lado, como un intento por democratizar el conocimiento científico y tecnológico entre el mayor número posible de miembros de una sociedad. De otro, como el intento de una comunidad científica por obtener el respaldo de diversos grupos sociales hacia su propio programa de investigación. En ambos casos, el espectáculo adquiere una finalidad epistémica, social y política que va mucho más allá del espectáculo mismo, y que de ningún modo se reduce a él, como sugiere Debord con su primera tesis.

\section{El caso de la propaganda.}

Piénsese ahora en lo que sucede con respecto al manejo que se hace de las relaciones públicas en un Estado, y en particular, lo que sucede con el caso de la propaganda. No es problemático en absoluto ubicar la propaganda en el esquema que ofrece Debord, pues él la toma explícitamente como una forma particular del espectáculo (Cap. 1, §6). Pero la propaganda constituye precisamente un uso paradigmático del espectáculo con fines que van mucho más allá del espectáculo mismo, y para defender esta tesis me apoyo en el modelo del mérito epistémico propuesto por Ross (2002).

La aproximación de Ross a la propaganda se origina en su interés por encontrar criterios para la educación artística que permitan distinguir entre el arte político y el arte propagandístico. Para esto, ella revisa definiciones previas sobre qué cuenta como propaganda en general, y encuentra que cada una de ellas es insuficiente debido principalmente a su incapacidad para delimitar el carácter peyorativo que le atribuimos a esta. Apoyada entonces en un modelo comunicativo clásico de emisor-mensaje-receptor, Ross ofrece una definición que busca dar un tratamiento más completo a la propaganda, incluyendo su carácter peyorativo.

En su definición, $\varphi$ cuenta como propaganda si y solo si $\varphi$ satisface cuatro criterios: (1) es un mensaje epistémicamente deficiente (2) que se emplea con la intención de persuadir (3) a un grupo de personas socialmente significativo sobre ciertas creencias, opiniones, deseos y comportamientos (4) en favor de una organización política, una institución política o una causa política. Ross sostiene que estas cuatro condiciones son suficientes y necesarias para identificar a $\varphi$ como propaganda, así que, si $\varphi$ no satisface al menos una de ellas, entonces $\varphi$ no contará como propaganda en absoluto.

El emisor en este modelo puede ser un individuo o un grupo, pero lo realmente determinante es que este emisor tiene una agenda política que beneficia a alguna organización, institución o causa. Esto le da un carácter eminentemente político a la propaganda. 
El receptor es un grupo de personas que resulta socialmente significativo para el emisor. Esto quiere decir que no todo grupo de personas jugará un rol en los procesos propagandísticos, sino solo aquellos grupos sobre los que el emisor ha decidido enfocarse de acuerdo con su propia agenda política.

Finalmente, el mensaje tiene por objeto persuadir a un grupo de personas acerca de la agenda política del emisor. Pero intenta alcanzar esta meta mediante la transmisión de mensajes que son epistémicamente deficientes, es decir, mensajes que pueden calificarse como falsas proposiciones, malos argumentos, juicios éticamente injustificados o metáforas inapropiadas para el contexto en cuestión. En general, mensajes que carecen de mérito epistémico debido a que intencionalmente buscan generar equívocos en el receptor.

La propaganda puede verse desde esta perspectiva como una forma de espectáculo, tal como sugiere Debord, y esto estaría justificado, siguiendo a Ross, en el uso constante que se hace de diferentes técnicas y expresiones artísticas para producirla. Pero justamente el modelo del mérito epistémico muestra que estas formas de espectáculo no se emplean en la propaganda por el espectáculo mismo. La propaganda tiene fines que van más allá de la propia propaganda. Con ella se busca transmitir mensajes que, a pesar de ser epistémicamente deficientes, logren persuadir a un público particular acerca de la agenda política asociada con una organización, una institución o una causa que determinado emisor está interesado en promover. Sin duda se recurre aquí al espectáculo, pero ese espectáculo es apenas un medio para alcanzar fines que se alejan radicalmente del propio espectáculo. Estos fines son políticos, y se configuran a partir de la manipulación que alguien hace de un grupo de personas en favor de otro grupo de personas. Una vez más, por tanto, es difícil concluir, como quiere hacerlo Debord con su primera tesis, que una forma de espectáculo como la propaganda no persigue ningún fin más allá de sí mismo.

\section{La dicotomía entre apariencia y realidad}

He indicado en la sección anterior que existen fenómenos como la comunicación científica y la propaganda en que, al contrario de lo que señala Debord, el espectáculo se emplea en las sociedades modernas con una finalidad que va más allá del propio espectáculo. Esto parece suficiente para dudar de su tesis sobre los fines del espectáculo, y por eso parece plausible intentar encontrar un mayor número de contraejemplos provenientes de otros contextos que contribuyan a minar dicha tesis. Sin embargo, mi interés aquí no es identificar más contraejemplos, sino pasar a su segunda tesis. Pues él además sostiene que el espectáculo justifica la creencia en una dicotomía entre apariencia y realidad.

La dicotomía entre apariencia y realidad es un tema recurrente en la historia de la filosofía, que puede retrotraerse cuando menos al mito platónico de la caverna. Sin embargo, como ya advertí antes, mi perspectiva en este artículo es analítica, y no propiamente histórica. Por ese motivo, basta con señalar acá que el tratamiento que reciba la dicotomía puede tener al menos dos vertientes: una epistemológica y otra ontológica.

En su vertiente epistemológica, la dicotomía se refiere a la dificultad que tenemos para identificar criterios irrebatibles que nos permitan asegurar de un modo indudable que hay un mundo exterior con todas las características que le atribuimos, o si más bien ese mundo exterior es una ilusión de nuestros sentidos. Siguiendo el ejemplo de la mesa de Russell (2008), la dificultad apunta a la posibilidad de preguntarse no solo cómo sé si hay realmente una mesa de cierto color y cierta forma frente a mí en este momento, sino además cómo sé qué tipo de objeto es esa mesa, si es un objeto material o mental.

Una versión más reciente de este problema, y cuyo antecedente se encuentra en la 
hipótesis cartesiana del genio maligno, recibe el nombre de cerebros en cubetas. Dancy (1993) lo presenta de la siguiente manera:

No sabemos que no somos cerebros, flotando en el líquido contenido en una cubeta de laboratorio, conectados con un computador que nos provee de las experiencias que tenemos en cada momento y bajo el control de algún técnico/científico inteligente (o bondadoso, o malévolo, dependiendo de los gustos de cada cual). No lo podemos saber porque, en el caso de que lo fuéramos y si el científico tuviera éxito, nada en nuestra experiencia nos revelaría que lo somos. Por hipótesis, nuestras experiencias serían idénticas a las de algo que no fuera un cerebro en una cubeta. Dado que cada uno de nosotros solo puede apelar a su propia experiencia, y como la experiencia es idéntica en cualquiera de las dos situaciones alternativas, nada hay que pueda revelar cuál de las situaciones es la que de hecho se da (p. 24).

El problema es, pues, cómo distinguir apariencia (el mundo de nuestras sensaciones) y realidad (el mundo en el que de hecho somos o no somos cerebros en una cubeta). Pero el epistemólogo usa este problema como un recurso para establecer criterios seguros de conocimiento. Su propósito no es realmente señalar una dicotomía insoslayable entre apariencia y realidad, lo que en última instancia viciaría todas nuestras pretensiones de conocimiento acerca del mundo exterior, sino más bien responder a casos extremos de escepticismo sobre la existencia del mundo exterior. Con ello el epistemólogo intenta explicar no solo por qué estamos justificados para creer que existe un mundo exterior, sino además que tenemos cierto grado de conocimiento de diversos aspectos de ese mundo exterior. La dicotomía adquiere así un carácter exclusivamente metodológico.

El énfasis de Debord en la dicotomía, en cambio, no es propiamente epistemológico, sino ontológico, y de allí saca consecuencias existenciales. Debord aborda la dicotomía con una certeza muy clara, una certeza de la que carece el epistemólogo. Él sabe que de hecho hay un mundo verdadero detrás del mundo de apariencias que nos proporciona el espectáculo. En otras palabras, mientras que el epistemólogo nos formula una pregunta: ¿cómo podemos saber si existe una dicotomía entre apariencia y realidad?, Debord nos plantea una afirmación, algo que él ya sabe de antemano y sobre lo cual no tiene ninguna duda en absoluto: existe una dicotomía entre apariencia y realidad. Y sin duda estas son dos posturas muy diferentes, pues al ignorar el problema epistemológico y concentrarse exclusivamente en el problema ontológico, Debord deja abierto un interrogante mucho mayor. Si de hecho él sabe que existe dicha dicotomía, la pregunta de inmediato es: ¿cómo lo supo?, ¿qué formas o medios de conocimiento lo llevaron a él a conocer esa dicotomía? En definitiva, ¿qué justifica su creencia en una dicotomía?

Esta pregunta se comprende mucho mejor si se tiene en cuenta que, de acuerdo con Debord, los ciudadanos de las sociedades modernas, al no tener medios para salir de la dicotomía $\mathrm{y}$ acceder al mundo verdadero, se encuentran irremediablemente en un estado de alienación tal que simplemente no pueden ni siquiera vivir su propia vida, sino solo aquella diseñada a su medida por el espectáculo. Como sucede con los héroes de películas famosas como The Matrix y The Truman Show, esos ciudadanos se encuentran en una situación desesperada: creen que todo aquello que los rodea es el mundo verdadero, pero no es más que una gran red de apariencias diseñada por otros para que actúen en su beneficio. $Y$ así como ocurre en esas películas, dado que ellos mismos no poseen los medios para hacerlo, necesitan de alguien más sabio que ellos, alguien externo a la red, para escapar a ese mundo de apariencias. Un alma caritativa que, por decirlo así, haya logrado ver ese mundo desde afuera y aun así al mismo tiempo haya decidido volver para rescatarlos. Sin embargo, Debord no explica en ningún momento cuál fue esa alma caritativa que le permitió a él escapar a la dicotomía y contemplar las cosas tal como son. 
El problema es, en suma, que existe una profunda tensión interna, casi una contradicción, en la segunda tesis de Debord. Pues a pesar de que él es un ciudadano más de esas sociedades modernas, al parecer también pudo romper con la dicotomía y acceder a un conocimiento del que carecen los demás ciudadanos y que no podrán alcanzar en ningún momento. Pero ¿por qué el ciudadano Debord? ¿Qué le permitió a él hacerlo y no a los demás? O como ya dije antes, ¿qué formas o medios de conocimiento lo llevaron precisamente a él a conocer esa dicotomía y escapar de ella, a diferencia del resto de los ciudadanos de estas sociedades? Desafortunadamente, él no ofrece ninguna respuesta a estas preguntas, y en cambio nos presenta su segunda tesis casi como un acto de fe, dado que, al no resolver la vertiente epistemológica de la dicotomía, resulta difícil comprender qué justifica su postura frente a la vertiente ontológica.

¿Qué revela entonces esta preocupación de Debord por la dicotomía entre apariencia y realidad? Creo que la respuesta la encontramos ya en Nietzsche (1985). Por ejemplo, en el tratamiento que este hace de la dicotomía en un pasaje bastante conocido de El ocaso de los idolos.

Para Nietzsche, la dicotomía surge no por un deseo real de parte de los filósofos por negar lo que existe, sino por su incapacidad para apropiarse de eso que existe. Ellos quieren fijarlo eternamente en una idea única e inamovible, una idea intemporal que les permita abarcarlo de una vez y para siempre. Sin embargo, la realidad fluye constantemente ante sus ojos, y por eso concluyen que ese devenir permanente indica que la realidad, el mundo verdadero, debe ser algo distinto, algo que se les resiste, pero que debe estar bajo esas apariencias con que los sentidos nos bombardean de un modo ininterrumpido.

El problema para el filósofo no es, pues, la existencia de ese mundo verdadero, inaccesible para nosotros por medio de los sentidos, sino precisamente los sentidos, pues su carácter intrínsecamente falible los hace engañosos. ¿Cómo sabemos entonces que ese mundo verdadero, que yace más allá de las apariencias, de hecho, sí existe? La respuesta que encuentra Nietzsche entre los filósofos es simple: porque le ha sido prometido al sabio, al que además le resulta accesible. El sabio tiene por tanto los medios para garantizar que ese mundo real sí existe, y eso basta para que nosotros, menos afortunados, podamos por lo menos concebirlo, aun cuando no tengamos ningún acceso directo a él. Es suficiente con que confiemos en lo que el sabio nos comunica. El sabio tiene los medios epistemológicos para alcanzar la certeza ontológica sobre la dicotomía. Y aunque nos comunica dicha certeza, nos priva siempre de conocer esos medios.

Sin embargo, Nietzsche (1985) rechaza tal dicotomía entre un mundo real y un mundo de apariencias. Y lo hace por razones que él resume en las siguientes cuatro tesis.

Primera tesis. Las razones por las que se ha considerado que "este" mundo es aparente constituyen más bien el fundamento de su realidad; cualquier otra forma de realidad resulta totalmente indemostrable.

Segunda tesis. Las características que son atribuidas al "verdadero ser" de las cosas son precisamente los rasgos distintivos del no ser, de la nada; el "mundo verdadero" ha sido concebido a base de contradecir el mundo real. Ese presunto "mundo verdadero" es en realidad un mundo aparente por no ser más que una ilusión de óptica moral.

Tercera tesis. No tiene sentido inventar fábulas respecto a "otro" mundo distinto a este, siempre y cuando no estemos movidos por un impulso instintivo a calumniar, a empequeñecer, a recelar de la vida. En este caso nos vengamos de la vida imagi- 
nando con la fantasía "otra" vida distinta y "mejor" que esta.

Cuarta tesis. Dividir el mundo en "verdadero" y "aparente", ya sea a la manera del cristianismo, ya sea al modo de Kant (en último término, un cristiano perverso), no es más que un índice de vida descendente. El hecho de que el artista valore más la apariencia que la realidad no representa una objeción a esta tesis, habida cuenta de que en este caso "la apariencia" equivale aquí también a la realidad, solo que seleccionada, reforzada, corregida. El artista trágico no es un pesimista; afirma todo lo problemático y terrible; es dionisíaco [...] (pp. 64-65).

Apelar al espectáculo para justificar la dicotomía entre apariencia y realidad no es más que, para emplear la terminología de Nietzsche, un índice de vida descendente, una manera de recelar de la vida que nos presentan nuestros sentidos. O para decirlo de otro modo, apelar al espectáculo para justificar la dicotomía no es más que renunciar precisamente a comprender la sociedad del espectáculo, sus dinámicas, sus fines, las estrategias que emplea para justificarse, reforzarse y perdurar en el tiempo. Pues el espectáculo se presenta aquí como una excusa para promover una división radical entre aquellos que saben, es decir, los sabios que tienen los medios epistemológicos para alcanzar certezas ontológicas sobre esta sociedad, y nosotros, que debemos aceptar pasivamente las certezas que ellos quieran comunicarnos. Pero una vez más, aunque ellos nos comunican dichas certezas, siempre nos privan de conocer los medios que les permitieron alcanzarlas. Nos privan, en definitiva, de los medios para tomar una postura crítica no solo frente a las certezas, sino además frente a los propios medios que se emplearon para llegar a ellas.

En suma, Debord no presenta una justificación clara para su segunda tesis. Y por eso parece mucho más fructífero seguir la recomen- dación de Nietzsche y aceptar que la sociedad del espectáculo es justamente aquello a lo que, para bien o para mal, podemos acceder de forma inmediata por medio de un uso crítico de nuestros sentidos. La postulación de un mundo verdadero diferente al nuestro, a ese que vemos cada día en las calles y en las pantallas de televisión, y para el cual requerimos de sabios que nos guíen hacia él y nos indiquen cómo funciona, nos aleja de la comprensión de los problemas más serios y apremiantes que enfrentan nuestras sociedades, y en última instancia lleva a que, por ejemplo, el quietismo, el paternalismo y el caudillismo se presenten como opciones perfectamente razonables y deseables. Pues si nuestra única puerta de acceso a ese mundo verdadero es el sabio, dependemos por completo de él para tomar decisiones sobre nuestras vidas privadas y sociales, y terminar así con el estado de alienación en que al parecer estaríamos inmersos.

\section{Conclusión}

Mi propósito en este artículo ha sido realizar una evaluación crítica de dos de las tesis que presenta Debord (1992) en su libro La société du spectacle. Estas tesis sostienen, primero, que el espectáculo no persigue ningún fin más allá de sí mismo, y segundo, que la prevalencia del espectáculo en las sociedades modernas justifica la creencia en una dicotomía entre apariencia y realidad.

Para evaluar estas dos tesis, he apelado a evidencia proveniente de la comunicación pública de la ciencia y la tecnología, la teoría de la propaganda y el análisis filosófico de conceptos. Esto ha permitido concluir dos cosas. Por una parte, hay ejemplos claros de que el espectáculo se emplea en las sociedades modernas con fines que van más allá del propio espectáculo. Por otra parte, hay una profunda tensión interna, casi una contradicción, en la postulación que hace Debord de una dicotomía entre apariencia y realidad, pues, aunque se afirma una certeza total respecto a la existencia 
de dicha dicotomía, no se explica en ningún momento qué justifica tal certeza. Dicho de una forma distinta, no se explica qué medios epistemológicos permitieron alcanzar esa certeza ontológica. Debord nos comunica la certeza, pero nos priva de conocer los medios que justifican su creencia en ella.

A pesar de esto, no es difícil concordar con Debord en que las sociedades modernas se caracterizan por ser sociedades donde $\sin$ duda prima el espectáculo. Este funciona en ellas como uno de los principales mediadores en un amplio número de aspectos que regulan las relaciones entre sus ciudadanos. Pero antes que postular una dicotomía entre apariencia y realidad, que se manifestaría a los ojos del filósofo por medio del espectáculo, parece ser que el análisis debe concentrarse en la función y los fines (positivos y negativos) del espectáculo en estas sociedades. Privar al espectáculo de tal análisis reduce nuestra capacidad de comprensión y de acción sobre estos asuntos.

Es importante tener en cuenta, sin embargo, que reconocer con espíritu nietzscheano que el mundo del espectáculo en que vivimos funciona tal como aparece ante nuestros ojos no significa que debamos aceptarlo tal como es, o que no podamos aspirar a un mundo diferente, quizá mejor. El espectáculo tiene diversos fines (epistémicos, éticos, políticos, existenciales, entre otros), y solo en la medida en que los identifiquemos y los sometamos a un escrutinio detallado podremos decidir qué hacer con ellos, si estamos de acuerdo o no con la configuración que hacen de nuestras sociedades. Recaer en viejas tesis metafísicas, que refuerzan el rechazo del mundo en que vivimos en beneficio de uno imaginario que está mucho más allá de nuestras capacidades cognitivas y políticas, no hace más que crear confusión sobre los verdaderos fines que se persiguen con el espectáculo en estas sociedades, y en última instancia nos impide comprender las dinámicas de poder y resistencia que lo impulsan y lo alientan.

\section{Nota}

1 Todas mis citas de este texto provienen de Debord (1992), pero en lugar de emplear los números de páginas, me referiré al capítulo y la tesis en el libro, para mayor facilidad de consulta y contraste por parte del lector. Emplearé paráfrasis del texto original, con la cita correspondiente en el original francés entre corchetes.

\section{Referencias}

Alcíbar, M. (2015). Comunicación pública de la ciencia y la tecnología: una aproximación crítica a su historia conceptual. Arbor, 191(773), 1-13.

Arias, L. M. (2011). La exclusión y la comunicación de la ciencia y la tecnología en un nuevo contrato social sobre la ciencia. Trilogía, 4, 155-167.

Cuevas, A. (2008). Conocimiento científico, ciudadanía y democracia. Revista Iberoamericana de Ciencia, Tecnología y Sociedad, 4(10), 67-83.

Dancy, J. (1993). Introducción a la epistemología contemporánea. Madrid: Tecnos.

Debord, G. (1992). La société du spectacle (3a ed.). Paris: Gallimard.

Durant, J. (1999). Participatory technology assessment and the democratic model of the public understanding of science. Science and Public Policy, 26(5), 313319.

Erazo, M. (2007). Comunicación, divulgación y periodismo de la ciencia. Una necesidad imprescindible para Iberoamérica. Quito: Planeta.

Golinski, J. (1992). Science as public culture: Chemistry and Enlightenment in Britain, 
1760-1820. Cambridge, Reino Unido: Cambridge University Press.

Hermelin, D. (2011). La comunicación pública de la ciencia y la tecnología en la formación en la comunicación social y en otras áreas del conocimiento. Trilogía, 5, 107-120.

Jappe, A. (1999). Guy Debord. (Trad. D Nicholson-Smith). Berkeley: University of California Press.

Jiménez, S., \&Palacio,M.(2010).Comunicación de la ciencia y la tecnología en museos y centros interactivos de la ciudad de Medellín. Universitas humanística, 69, 227-257.

Kaplan, R. (2012). Between mass society and revolutionary praxis: The contradictions of Guy Debord's Society of the Spectacle. European Journal of Cultural Studies, 15(4), 457-478.

Lozano, M. (2008). El nuevo contrato social sobre la ciencia: retos para la comunicación de la ciencia en América Latina. Razón y palabra, 65(13). Recuperado de http://www.redalyc.org/articulo. oa? id=199520724009

Nietzsche, F. (1985). El ocaso de los ídolos. Madrid: Busma.

Olivé, L. (2003). Por un nuevo contrato social sobre la ciencia y la tecnología. Ciencia y desarrollo, 172, 7-12.
Perrault, S. (2013). Communicating popular science: From deficit to democracy. Reino Unido: Palgrave Macmillan.

Pinzón, A., Franco-Avellaneda, M., \& Falla, S. (2015). Condiciones que posibilitan el acceso a un museo de ciencias: análisis del caso Maloka. Trilogía, 7(12), 11-27.

Rider, R. E. (1990). El experimento como espectáculo. En J. Ordóñez \& A. Elena (Eds.), La ciencia y su público (pp. 113146). Madrid: CSIC.

Ross, S. T. (2002). Understanding propaganda: The epistemic merit model and its application to art. Journal of Aesthetic Education, 36(1), 16-30.

Rueda, X. A. (2016). La comunicación de la ciencia y la tecnología como herramienta dialógica para la Apropiación Social de Ciencia, Tecnología e Innovación (ASCTeI) en Comunidad Mixe, México. Trilogía, 8(15), 119-128.

Russell, B. (2008). The problems of philosophy. Radford, VA: Wilder Publications.

Ursua, N. (2004). Divulgación de la ciencia, la ciencia y el público. Algunos problemas teóricos. En A. Alonso \& C. Galán (Eds.), La tecnociencia y su divulgación: un enfoque transdisciplinar (pp. 53-96). Madrid: Anthropos. 